Original Research Article

\title{
Analysis of prescribing pattern of antimicrobial agents and its rationality in tertiary care rural setup of Central India
}

\author{
Nitin D. Pise*, Swapnil B. Kaikade
}

Department of Pharmacology, ACPM Medical College, Dhule, Maharashtra, India

Received: 09 June 2017

Revised: 23 June 2017

Accepted: 07 July 2017

*Correspondence to:

Dr. Nitin D. Pise,

Email: dr_nitinpise@yahoo.in

Copyright: (C) the author(s), publisher and licensee Medip Academy. This is an openaccess article distributed under the terms of the Creative Commons Attribution NonCommercial License, which permits unrestricted noncommercial use, distribution, and reproduction in any medium, provided the original work is properly cited.

\begin{abstract}
Background: Antimicrobial agents are most commonly prescribed drug and share major cost of the treatment. Excessive and inappropriate use of antimicrobial has become a global problem, resulting not only in substantial economic burden on healthcare system but also in contributing to the selective pressure favoring the emergence of antibiotic-resistant microorganisms. Antimicrobial agents which one uses for prophylactic, empiric and therapeutic purposes, depends upon the local epidemiology of infectious diseases, microbiology and resistance pattern as well as local clinical experience. Rational use of antibiotics is one of the most important way of preventing development of resistant strains to these drugs. However, for this, the health care providers should be aware of the available antibiotic prescription guidelines and should strictly adhere to it. Also, they should be updated of emerging resistant strains. Though the strict guidelines are available for the use of antibiotics, there are differences in level of knowledge and approach to antibiotic prescription among professional health care providers.

Methods: The present cross sectional study was carried out in A.V.B.R. Teaching Hospital by collecting data from admitted patient's case paper, tabulated in seven groups of diseases and different groups of antimicrobial agents prescribed.

Results: Penicillin and quinolone group of antimicrobials show maximum use whereas sensitivity found more in cephalosporins and quinolone group of antimicrobials.

Conclusions: It was found that Cephalosporins ( $3^{\text {rd }} \mathrm{Gen}$.) are the most commonly prescribed antimicrobial agents followed by aminoglycosides (Gentamicin) and Fluroquinolones (Ciprofloxacin).
\end{abstract}

Keywords: Antimicrobials, IPD patients, Prescription pattern

\section{INTRODUCTION}

Antimicrobials are among the most commonly prescribed drugs accounting for $28 \%$ to $42 \%$ of total drug prescriptions and also among the drugs consuming a major cost share of treatment both for public hospital and individual patients. Excessive and inappropriate use of antimicrobial has become a global problem, resulting not only in substantial economic burden on healthcare system but also in contributing to the selective pressure favoring the emergence of antibiotic-resistant microorganisms. ${ }^{1,2}$
Antimicrobial agents which one uses for prophylactic, empiric and therapeutic purposes, depends upon the local epidemiology of infectious diseases, microbiology and resistance pattern as well as local clinical experience. ${ }^{3}$ Rejecting certain types of clinical specimens such as sputum specimens with excessive epithelial cells will also avoid misleading clinicians and may decrease the use of unnecessary antimicrobials, which would save the institution's money. ${ }^{4}$ Best choice of antimicrobial agents must be based on experience and on knowledge of current antibiotic susceptibility of the more likely causes of the 
infection. ${ }^{5}$ There should be restriction on antibiotic use, which are resistant. Such type of strategy is very effective in controlling antibiotic resistance. ${ }^{6}$ The present work is undertaken with a view to study prescribing pattern of antimicrobial agents and its rationality to make recommendation for the proper therapeutic strategy of antimicrobial agents for further use in Acharya Vinoba Bhave Rural (A.V.B.R.) Teaching Hospital, Wardha.

\section{Objectives}

- To study the prescribing pattern of antimicrobial agents and its rationality in teaching hospital.

- To minimize antimicrobial resistant microorganism.

- To recommend the proper therapeutic strategy of antimicrobial agents.

\section{METHODS}

The present cross sectional study was carried out in A.V.B. R Teaching Hospital of J.N.M.C., Sawangi (Meghe), Wardha by collecting data from admitted patient's case paper in standardized, uniform and meaningful manner to obtain information about quantitative and qualitative aspects of prescribing pattern of antibiotics. The antimicrobial agents given to the patients in our study are classified into four main groups:

- Aminoglycosides: Amikacin, Gentamicin

- Cephalosporins: Cefotaxime, Cephalexine

- Penicillins: Amoxycillin, Ampicillin

- Quiolones: Ciprofloxacin, Norfloxacin, Ofloxacin

Table 1: Seven different group of diseases.

\begin{tabular}{|ll|}
\hline Groups of diseases & Different diagnosis \\
\hline Lung infections & $\begin{array}{l}\text { Lower respiratory tract } \\
\text { infections, bronchopneumonia, } \\
\text { pleural effusion. }\end{array}$ \\
\hline $\begin{array}{l}\text { Gastrointestinal } \\
\text { tract infections }\end{array}$ & $\begin{array}{l}\text { Acute gastroenteritis, acute } \\
\text { amoebic dysentery, infective } \\
\text { diarrhoea, colitis. }\end{array}$ \\
\hline $\begin{array}{l}\text { Skin and Soft tissue } \\
\text { infections }\end{array}$ & $\begin{array}{l}\text { Tubercular ulcer, cellulitis, } \\
\text { abscess, burn, wound infections. }\end{array}$ \\
\hline $\begin{array}{l}\text { Upper respiratory } \\
\text { tract infections }\end{array}$ & $\begin{array}{l}\text { Pharyngitis, tonsillitis, } \\
\text { bronchitis, upper respiratory } \\
\text { tract infections (URTI). }\end{array}$ \\
\hline $\begin{array}{l}\text { Urogenital tract } \\
\text { infections }\end{array}$ & $\begin{array}{l}\text { Cervicitis, orchitis, urinary tract } \\
\text { infections (UTI), vaginitis, } \\
\text { urethral stricture, prostitis. }\end{array}$ \\
\hline Enteric fever & Typhoid, enteric fever. \\
\hline Postoperative & $\begin{array}{l}\text { Peritonitis, fractures, } \\
\text { appendicitis, LVH, RVH, BPH, } \\
\text { LSCS, intestinal obstruction, } \\
\text { MTP with TL, fibroid, } \\
\text { gangrene. }\end{array}$ \\
\hline
\end{tabular}

Data was collected from case paper records of 300 patients admitted in different disciplines-Medicine, Pediatrics,
Obstetrics and Gyanecology, Orthopedics, Ophthalmology and ENT.

For this study, the data was collected from Medical Record (M.R.) section for the period of 18 months. Selected seven broad groups of diseases, considered following diagnosis.

In Table 1 there were selected seven groups of diseases and the diagnosis.

For these seven groups of diseases, it was analyzed the no. of agents used in empirically prescribed therapy.

\section{RESULTS}

The data of 300 patients regarding their diagnosis and treatment, was collected from admitted patients in Medicine, Pediatrics, Obstetrics and Gynecology, Surgery, Orthopedics, Ophthalmology and ENT, is tabulated.

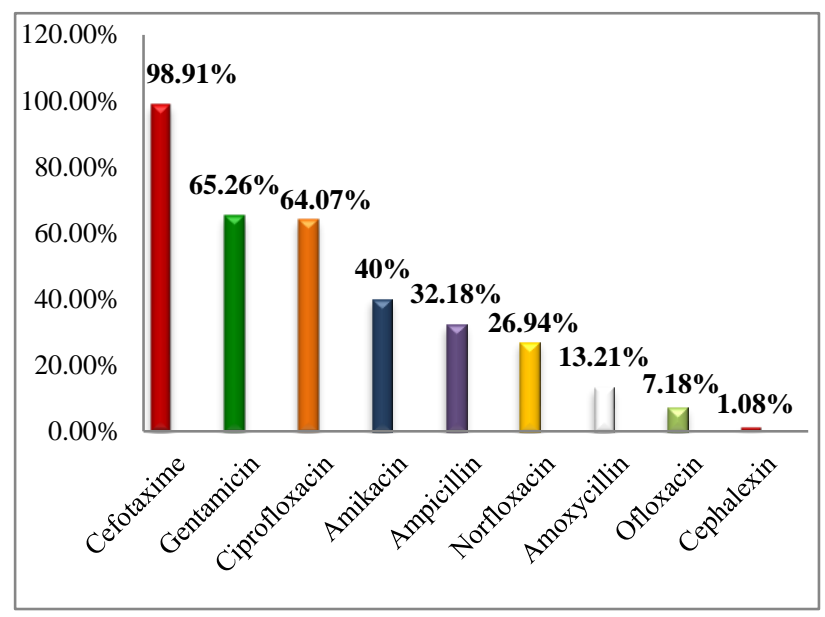

Figure 1: Percentage of prescribing frequency of antimicrobial agents.

Figure 1 Shows maximum frequency of prescribing Cefotaxime (98.91\%), Gentamicin (65.26\%) and Ciprofloxacin $(64.07 \%)$.

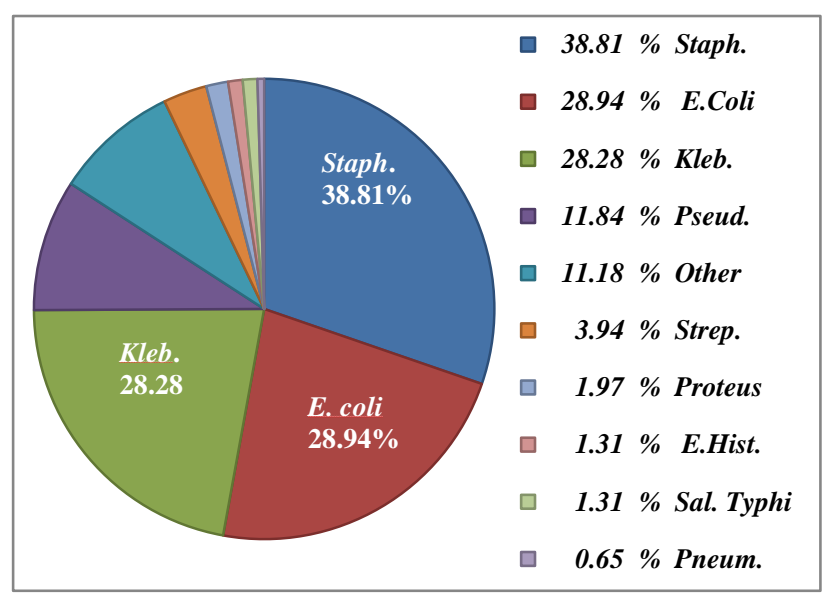

Figure 2: Commonly found organism. 
Figure 2 shows Staphylococci, E. coli then Klebsiella to be seen for maximum number of time i.e. $38.81 \%, 28.94 \%$ and $28.28 \%$ respectively.

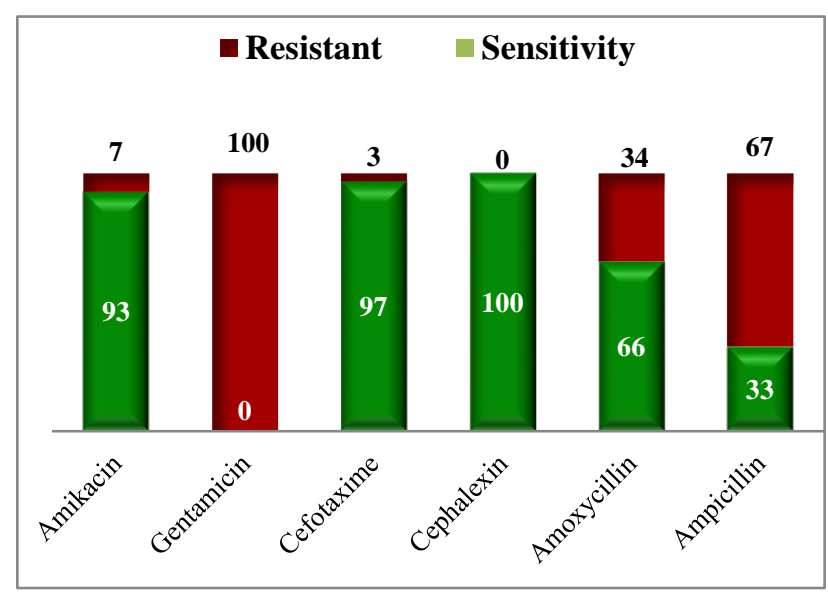

Figure 3: Percentage of sensitivity and resistance pattern of antimicrobial agents.

Figure 3 organisms show maximum sensitivity to Cephalexin (100\%), Cefotaxime (97\%) and Amikacin (93\%). And totally resistant to Gentamicin (100\%) and $67 \%$ to Ampicillin.

\section{DISCUSSION}

A prescription by a doctor may be taken as summary of physician's attitude to the disease and role of drug in the treatment. It also provides an insight into the nature of the health care delivery system. ${ }^{7-9}$ The current study shows frequent use of Cefotaxime (98.91\%), Gentamicin (65.26\%) and Ciprofloxacin (64.07\%) Dawadi Sushma, et al, has studied six different antimicrobials and reported the most commonly used group as Penicillins (47.36\%) followed by Tetracycline (43.15\%), Macrolides (4.2\%), Quinolones $(3.1 \%)$ and Cephalosporins (2.1\%). E. coli, Kleb. and Staph. organisms found maximally sensitive to Cephalexin (100\%), Cefotaxime (97\%), and Amikacin (93\%) while, totally resistant to Gentamicin. Kollef $\mathrm{MH}$, et al, demonstrated a 6 statistically significant association between the initial prescription of inadequate antimicrobial and hospital mortality. The use of such antimicrobials initial to the culture sensitivity test lead to unnecessary increase in the bacterial resistance. In the study by Michael BE, et al, the most common organisms found were Staphylococci (32\%), Staphylococcus aureus (16\%) and Enterococci (11\%). In the current study, it is observed that most common organism found in all the samples tested were Staphylococci $(38.81 \%)$, E. coli $(28.94 \%)$ then Klebsiella $(28.28 \%)$. This is important so as to decide the antibiotic therapy. Antimicrobials having maximum sensitivity against these organisms should give preference.
This suggests that antimicrobials should be preferably prescribed after culture sensitivity test so as to avoid development of resistance and treatment failure. In the current study Staphylococci, E. coli then Kleb. are found to be most commonly found organism in the samples, which can help us as a guideline for prescribing antimicrobial therapy.

Funding: No funding sources

Conflict of interest: None declared

Ethical approval: The study was approved by the Institutional Ethics Committee

\section{REFERENCES}

1. Harmeet SR, Nagarani MA, Moushumi R. A study on the drug prescribing pattern and use of antimicrobial agents at a tertiary care teaching hospital in eastern Nepal. Indian Journal of pharmacology. 1998 May 1;30(3):175.

2. Hamilton Miller JMT: Use and abuse of antibiotics. Br. J. Clin. Pharmac. 1984;18:469-74.

3. World Health Organization: Health situation in South East Asia region; 2000:185.

4. Evans RS, Pestotnik SL, Classen DC, Clemmer TP, Weaver LK, Orme Jr JF, et al. A computer-assisted management program for antibiotics and other antiinfective agents. New England Journal of Medicine. 1998 Jan 22;338(4):232-8.

5. Reller LB, Weinstein MP, Peterson LR, Hamilton JD, Baron EJ, Tompkins LS, et al. Role of clinical microbiology laboratories in the management and control of infectious diseases and the delivery of health care. Clinical infectious diseases. $2001 \mathrm{Feb}$ 15;32(4):605-10.

6. Gross PA. The potential for clinical guidelines to impact appropriate antimicrobial agent use. Infectious disease clinics of North America. 1997;11(4):803-12.

7. World Health Organization: Emerging and other communicable diseases-Antimicrobial Resistance Executive Board. 1998;9:451.

8. McGowan Jr JE, Finland M. Usage of antibiotics in a general hospital: effect of requiring justification. Journal of Infectious Diseases. 1974 Aug $1 ; 130(2): 165-8$.

9. Laporte JR. Towards a healthy use of pharmaceuticals. Development dialogue. 1985;2:48-55.

Cite this article as: Pise ND, Kaikade SB. Analysis of prescribing pattern of antimicrobial agents and its rationality in tertiary care rural setup of Central India. Int J Basic Clin Pharmacol 2017;6:2289-91. 